\title{
Determinants of happiness among youth in Malaysia
}

\begin{abstract}
This study was conducted to identify factors associated with happiness among urban youth in Malaysia. Respondents were 400 youth community-dwelling residents in the metropolitan areas of Malaysia. Structural equation modelling was used to analyse the data. Findings showed that social and family environments and education predict the happiness of young adults. Surprisingly, the results also revealed a significant negative relationship between economic opportunities and their happiness, while health, ICT use, and civic engagement had no significant effect on their happiness. Our findings support the implementation of actions to stimulate social and family environments, education, and economic opportunities for young urban adults in Malaysia, particularly given the importance of these factors in the perception of their happiness.
\end{abstract}

Keyword: Happiness; Subjective well-being; Urban youths; Malaysia 